Saudi Journal of Medical and Pharmaceutical Sciences

Abbreviated Key Title: Saudi J Med Pharm Sci

ISSN 2413-4929 (Print) |ISSN 2413-4910 (Online)

Scholars Middle East Publishers, Dubai, United Arab Emirates

Journal homepage: https://saudijournals.com

Case Report

\title{
Cervical Cellulitis Revealing Hodgkin's Lymphoma
}

${\text { Mohamed Ali Gliti }{ }^{1 *} \text {, Razika Bencheikh", }}^{2}$, Ahmed Ould Mohamed ${ }^{1,3^{*}}$, Benbouzid Mohamed Anas ${ }^{2,3}$, Leila Essakalli Houssyni ${ }^{2,3}$

${ }^{1}$ Resident Physician in Otorhinolaryngology, Department of Otorhinolaryngology, Head and Neck Surgery, Ibn Sina University Hospital, Rabat, Morocco

${ }^{2}$ Professor of Otorhinolaryngology, Department of Otorhinolaryngology, Head and Neck Surgery, Ibn Sina University Hospital, Rabat, Morocco

${ }^{3}$ Faculty of Medicine and Pharmacy of Rabat, Mohammed V University, Rabat, Morocco

DOI: $\underline{10.36348 / \text { simps.2021.v07i01.015 }}$

| Received: 04.01.2021 | Accepted: 18.01.2021 | Published: 29.01.2021

*Corresponding author: Mohamed Ali Gliti

\section{Abstract}

Adult cervicofacial cellulitis is most often from a dental origin or infectious, but in some rare cases, it can be paraneoplastic or from a tumor. We report the case of a 31-year-old young man who presented with right cervical cellulitis associated with bilateral thyroid nodules classified TIRADS 4 and associated thymic hyperplasia. In this observation, the diagnosis of Hodgkin lymphoma (HL) was not initially made due to a diverse clinical semiology associating several diffuse cervical lesions, and an infectious context contradictory to the presentation typical of isolated peripheral cervical lymphadenopathy. Thus, the etiology of HL should be kept in mind when considering head and neck cellulitis.

Keywords: Cervicofacial cellulitis, Hodgkin lymphoma (HL), cervical lymphadenopathy.

Copyright () 2021 The Author(s): This is an open-access article distributed under the terms of the Creative Commons Attribution 4.0 International License (CC BY-NC 4.0) which permits unrestricted use, distribution, and reproduction in any medium for non-commercial use provided the original author and source are credited.

\section{INTRODUCTION}

Head and neck cellulitis are infections of the cellulo-adipose tissue of the head and neck. These are serious conditions that tend to spread rapidly and can be life-threatening.

They can be postoperative, post-traumatic, tumor or can follow a skin infection or ENT; nevertheless, these causes remain rare and are largely preceded by dental origin [1-3].

\section{Case Report}

This is a 31-year-old patient with no notable pathological history, friends in the emergency department with a picture of right lateral-cervical cellulitis, complicating a mass that appeared four days ago.

Clinical examination found a mass $4 \mathrm{~cm}$ in size, the skin opposite is inflamed, painful on palpation, of a persistent consistency in the center and firm in the surroundings, poorly limited, fixed to the superficial and deep plane (Figure-1).

The patient was generally febrile with a fever estimated at 39 degrees Celsius, thrill, with general deterioration, associated with anorexia and previous unstated weight loss.

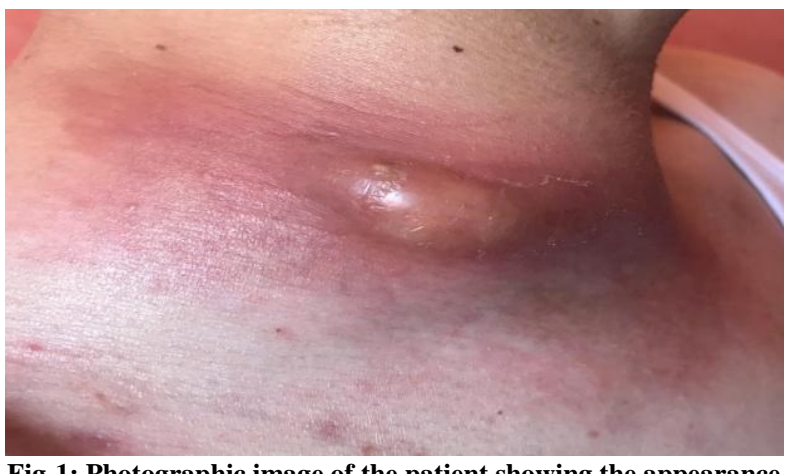

Fig-1: Photographic image of the patient showing the appearance of cervical cellulitis

An emergency CT scan was performed showing a large right supraclavicular lymphadenopathy of metastatic appearance measuring $5 \mathrm{~cm}$ long axis, as well as another lymphadenopathy of the homolateral jugular carotid and spinal territories. Moreover, we found a multi-nodular thyroid, and on the thoracic level, the CT Scan showed also a $2 \mathrm{~cm}$ thymic nodule. Besides, the larynx and the cavum were normal (Figure2). 


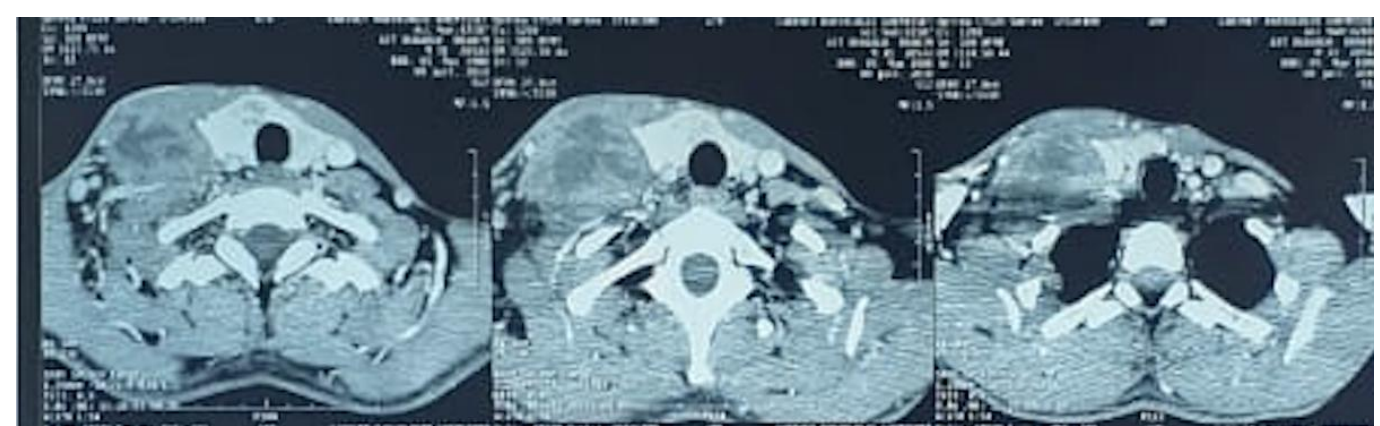

Fig-2: Image of a cervicothoracic CT scan with an injection of contrast product in axial section showing a large right supraclavicular lymphadenopathy, a multi-nodular thyroid, and a $2 \mathrm{~cm}$ thymic nodule

Given the imaging data (lymph node, thyroid, and thymic involvement), a cervical ultrasound was requested showing a right supraclavicular lymphadenopathy collected as well as an ipsilateral lateral jugular lymphomatous appearance. At the thyroid level, she found three nodules (a central lobe and lower right polar $13+21+29 \mathrm{~mm}$ and 2 lower left poles of $6 \mathrm{~mm}+6 \mathrm{~mm}$ and $3.5 \mathrm{~mm}+2.4 \mathrm{~mm}$ respectively) (Figure-3).

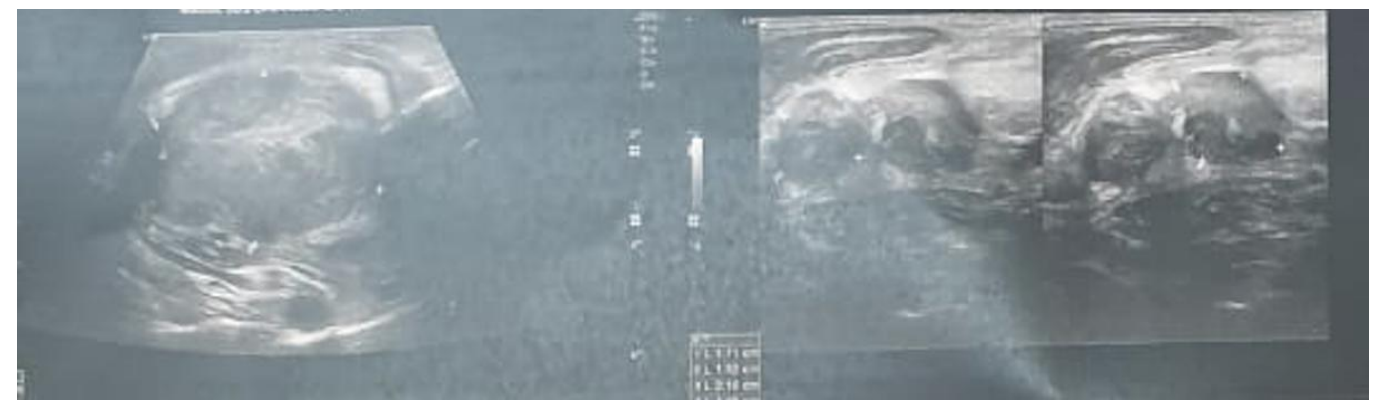

Fig-3: Ultrasound image showing right supraclavicular lymphadenopathy of an oval shape, poorly limited, hypoechogenic echostructure

Biologically the patient presented with hyperleukocytosis at 12.93 miles, as well as an inflammatory syndrome, where the rate of sedimentation is high ( $45 \mathrm{~mm}$ at the first hour and 85 at the second) an elevated CRP at $39 \mathrm{mg} / \mathrm{l}$. The antihepatitis $\mathrm{B}$ and $\mathrm{C}$ serology, as well as the anti-HIV serology, returned negative.

On the therapeutic level, the patient first received medical treatment based on amoxicillin with clavulanic acid at a dose of $1 \mathrm{~g}$ every 6 hours combined with paracetamol at a dose of $1 \mathrm{~g}$ every 6 hours administered intravenously. The patient underwent a biopsy curettage of the purulent collection, which returned nonspecific (suppurative necrosis), and GeneXpert examination also, to look for a tuberculous origin, but she also came back negative. Surgically, a large Paule André-type cervical incision was made to allow both total thyroidectomy and cellulo lymphadenectomy for cervical lymphadenopathy to be performed. The extemporaneous examination of the lymphadenopathy returned in favor of inflammatory adenitis without a sign of malignancy, the extemporaneous examination of the left thyroid lobe returned in favor of benign nodules.

The definitive pathological examination with an immunohistochemical study revealed classic Hodgkin lymphoma of the sclero-nodular type. The result of the pathological examination of both thyroid lobes in favor of benign multi-nodular macro-vesicular hyperplasia.

The patient was referred to the internal medicine department where the ABVD type first-line chemotherapy protocol (adriamycin, bleomycin, vincristine, and dacarbazine) was administered on Day 1 and Day 15 since the protocol is based on two cures. The follow up was marked by the onset of fever during the chemotherapy and the diagnosis of sepsis was assessed and treated.

\section{DiscUSSION}

Hodgkin lymphoma (HL) is revealed in $80 \%$ of cases by peripheral lymphadenopathy (cervical, supraclavicular most often), in $10 \%$ of cases by mediastinal lymphadenopathy, discovered on a systematic chest X-ray or the occasion of signs of compression (cough, dyspnea, pain), finally in 10 to $20 \%$ of cases by general signs, such as fever, night sweats, weight loss and more rarely itching or pain on ingestion of alcohol.

Although the cure rate of patients with HL, all stages combined, is $75 \%$, the excess mortality observed beyond 15 years is mainly linked to the appearance of second cancers and cardiac complications [5]. These 
data have led to reconsider certain therapeutic strategies [4].

Neoplasms diagnosed in the thyroid gland are usually primary thyroid cancers, while lymphomas represent less than $5 \%$ of malignant lesions diagnosed. Most of them are non-Hodgkin's B-cell lymphoma (NHL), most commonly developing during autoimmune thyroiditis, while HL, mainly localized in the thyroid, is a very rare finding $[6,7,8]$.

Clinical and pathological manifestations of thyroid disease with lymphoid infiltrates, such as malignant lymphoma, Graves' disease, Hashimoto's thyroiditis, or de Quervain's subacute thyroiditis, have been well established. Still, typical clinical features of reactive lymphoid hyperplasia of the thyroid gland have not been described yet. Thus, the differential diagnoses clinically with thyroid tumor or goiter, and pathologically with malignant lymphoma are mandatory [9].

Primary lymphomas represent 1 to 5 percent of thyroid tumors. Most cases occur in patients who have chronic thyroiditis, and there is a distinct female predominance [10]. Pathologically, most thyroid lymphomas are of non- Hodgkin's B-cell origin [11]. In the in our case, differential diagnosis from malignant lymphoma was critical. However, follicular malignant lymphoma should be excluded because of the morphology of the cells, presence of mitosis, or tingible body macrophage. Moreover, the immunohistochemical features, such as normally located bcl-2-positive cells only at the marginal zone, or preserved dense dendric cell net- work clearly demonstrated the non-tumoral nature of the lymphoid infiltration, and was enough to rule out malignant lymphoma.

In the thymus, all types of lymphoma can be found, but the three most common are HL, type B large cell lymphomas, and lymphoblastic lymphomas (type T). The most common HL are almost always of the scleronodular type (stage III in the Lukes classification). Large cell NHL is characterized by type B cells with intense fibrosis [12].

\section{Conclusion}

The clinical presentation of HL in the form of cervical cellulitis is rare or even exceptional. This observation shows the need to evoke, in the presence of any cellulitis, a suspected cervical tumor, a possible HL. Also, the diverse clinical semiology associating several diffuse cervical lesions with ganglionic, thyroid, and thymic involvement, and an infectious context contradictory to the typical presentation of isolated peripheral cervical lymphadenopathies should suggest HL.

\section{REFERENCES}

1. Subhashraj, K., Jayakumar, N., \& Ravindran, C. (2008). Cervical necrotizing fasciitis: An unusual sequel of odontogenic infection. Med Oral Patol Oral Cir Bucal. 13(12): E788-91.

2. Zeitoun, I. M., \& Dhanarajani, P. J. (1995). Cervical cellulitis and mediastinitis caused by odontogenic infections: report of two cases and review of literature. Journal of oral and maxillofacial surgery, 53(2), 203-208.

3. Yamaoka, M., Furusawa, K., Uematsu, T., \& Yasuda, K. (1994). Early evaluation of necrotizing fasciitis with use of CT. Journal of CranioMaxillofacial Surgery, 22(5), 268-271.

4. Fermé, C., \& Reman, O. (2004). Lymphome de Hodgkin de l'adulte. EMC-Hématologie, 1(4), 115-134.

5. Henry-Amar, M., Aeppli, D. M., Anderson, J., Ashley, S., Bonichon, F., Cox, R. S., ... \& Löffler, M. (1990). Workshop statistical report. In Treatment strategy in Hodgkin's disease (Vol. 196, pp. 169-428). INSERM/John Libbey Eurotext London, Paris.

6. Szczepanek-Parulska, E., Szkudlarek, M., Majewski, P., Breborowicz, J., \& Ruchala, M. (2013). Thyroid nodule as a first manifestation of Hodgkin lymphoma-report of two cases and literature review. Diagnostic pathology, 8(1), 1-8.

7. Forconi, F., Bocchia, M., Marconcini, S., Bigazzi, C., Milani, M., Fraternali-Orcioni, G., \& Lauria, F. (1999). CD30 positive (non-anaplastic) peripheral T-cell lymphoma of the thyroid gland. Haematologica, 84(10), 946-948.

8. Derringer, G. A., Thompson, L. D., Frommelt, R. A., Bijwaard, K. E., Heffess, C. S., \& Abbondanzo, S. L. (2000). Malignant lymphoma of the thyroid gland: a clinicopathologic study of 108 cases. The American journal of surgical pathology, 24(5), 623-639.

9. Onoda, N., Ohsawa, M., Kawajiri, H., Noda, S., Kashiwagi, S., Takashima, T., \& Hirakawa, K. (2014). Reactive lymphoid hyperplasia of the thyroid followed by systemic autoimmune diseases: a case report. Journal of Medical Case Reports, 8(1), 1-6.

10. Malloy, K. M., \& Cunnane, M. F. (2008). Pathology and cytologic features of thyroid neoplasms. Surgical oncology clinics of North America, 17(1), 57-70.

11. Mack, L. A., \& Pasieka, J. L. (2007). An evidence-based approach to the treatment of thyroid lymphoma. World journal of surgery, 31(5), 978-986.

12. Perrotin, C., \& Régnard, J. F. (2005). Tumeurs du thymus. EMC-Pneumologie, 2(1), 33-48. 